\title{
Study on the Function of Network Graffiti from the Perspective of Totem Spirit
}

\author{
Wu Liu \\ Jingdezhen Ceramic Institute, Jingdezhen, Jiangxi Province 333403
}

Keywords: Network graffiti; Experience activities; Totem spirit; Re-tribalization

\begin{abstract}
Network graffiti is a relatively new interactive experience activity, there are hundreds of thousands of online communities to provide this interactive experience platform. Repressed by the reality of modern society in the pursuit of specialization and diversification, then the people who is in the emergence of "alienation", the loss of freedom and unique combination of human beings will put their heart into the network graffiti in the unconscious situation, and formed a common spiritual pillar and code of conduct of the sub-cultural groups, in the experience process, the freedom of the experience is highly reflected, the purpose of its experience become more purely. And the spirit of cohesion network graffiti experience is totem spirit, the common persistence and pursuit of the experience.

With the development of the Internet age, a series of interactive interactive experience activities are born, network graffiti is one of the most representative. Modern society tends to specialization and diversification, with specialized technology and distinctive signs, pay attention to efficiency and practical, inner complex emotions have long been suppressed by the pressure of the reality, tortured, resulting in human division, and the emergence of human "alienation". As McLuhan's third phase of the human culture process, the advent of the electronic media era, there has been a re-tribe phenomenon. He believes that the electronic media is an extension of the central nervous system, the whole human again have been connected together, compared to the oral spread of the tribal era, re-tribe is the spiral rise and progress of social culture. The network community, as one of the carriers of the electronic media era, carries the characteristics of the re-tribalization, and when blending with other media, it has unprecedented social functions and responsibilities. In this era, people are no longer satisfied to be a split cut, incomplete person, beginning to yearn for freedom, eager to the self-all-round development, to resist the specialization and diversification.
\end{abstract}

\section{Online Community}

Network community is a new type of social structure that is widely circulated in the world. This social structure stems from the interaction between social organization, social change and the technical pattern formed by digital information and communication technology. It is treating information as human social activities to form social networks and information networks. The primitive society treats the blood as the link and base with a clear geographical distribution, name, religious beliefs, dialects and customs, is a hierarchical social class. These two kinds of social structures generally have simple social relations, people living in a certain extent, and are closely related. The tribes of the primitive society are gregarious because of the material needs, and their totem spirit is only to be able to understand the outer world and thus better to survive. While in the online community, people yearn for the fullness of the spiritual world, is the spiritual flash of the spirit freedom to fly, the reason why the nature of human. Slowly, it became a sanctuary for "alienated" people.

As we all know, people's gathering and even the generation of groups, community are organized around the shared interests or objectives. Through the interaction, they gradually found like-minded people, and form tribes. With the passage of time, the original purpose of surfing Internet will gradually dilute, people will gradually demand for personal support, and people who share the same interest to surf the Internet. Internet space compared with the reality is virtual, emphasizing one kind of "alternative" role in reality. Interpersonal relationships in the community are more important than the information that the network spreads, so the online community not only provides the place 
and technical support simply, but the processing and transmission of information, is the shaping and control of the scale and form of the combination and behavior of the people, network graffiti as one of the contents of the online community, its form and use can be varied, but its ultimate role in the experience can not be replaced.

\section{Network Graffiti under the Influence of Re-Tribalization}

"Art is a kind of compensation for the pain of life, and art is one of the buffering measures that mankind provides in order to endure the hardships of life." The network graffiti is a kind of counterfeiting through the search for a comfortable strategy to meet the fantasy desire to compensate for the suffering of people, so that people can survive. And they began to develop to the both ends of the daily aesthetic and removal aesthetic development.

On the one hand, McLuhan said: "We have shaped the tools, and then the tool has shaped us." The human senses are highly inflated by the expansion of the various types of information brought about by the highly developed electronic media. In the field of aesthetics, in the face of a lot of information people have to judge and appreciate, their aesthetic activities can not help but affected. And the content and scope of aesthetic activities in the era of electronic media has been unprecedentedly increased, its strong transmission capacity will integrate people's daily life into the aesthetic activities, blurred the daily life and aesthetic boundaries, there has been aesthetic daily life and daily aesthetic of life, making the aesthetic and daily life towards unity.

On the other hand, network graffiti as an experiential activity, used to interpret emotions and desires, is unique form of activity accompanied by removal aesthetic and the continuous unity of daily life. With the help of the network, it shows the characteristics of traditional graffiti. It is a mirror of self, not socially constrained, nor socially dominated, and is a destructive activity of the desire for beauty. While this kind of aesthetic activities is to better understand enjoy themselves.

The happy atmosphere whether it is the pursuit of aesthetic experience of the network graffiti or the graffiti activities to remove aesthetic of the network of, according to Marx's theory of human development, the ultimate goal of human development is the development of free personality, and this is the ultimate pursuit of network of totem spirit of network graffiti. Internet graffiti has become the art extension of the central nervous system, re-tribe is the whirlpool rise and progress of the social culture. This trend of the development of the community has created a network of graffiti

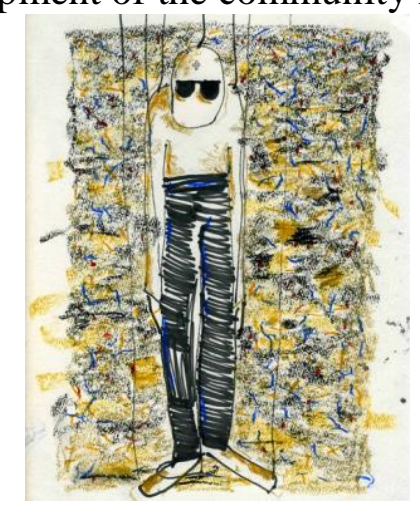

Figure 1. Totem spirit work

Atmosphere, and the indispensable conditions and environment to develop network graffiti with a variety of styles of indispensable conditions and the environment.

\section{The carrier of market interaction}

Internet community because of its different functions, provided different places and a variety of possibilities for different areas of the network graffiti, making their experience creativity and emotional expression get the carrier for interactive expression, compared with the traditional graffiti forced aggressiveness, the network community provides the possibilities of the rationalization and legalization for the development of network graffiti. 
Marc Ecko is a graffiti artist who has implanted a clip on a portable camera on the Internet, where Ecko made the graffiti on President Bush's jet plane with "still free". Using a destructive approach, Ecko naturally became a hot topic. According to statistics, the video site's click frequency broke through 23 million, while the experience of access to 23 million broadcast audiences and 90 million of the flat audience. In the spread of this virus in the network, even in a small medium, it can produce a huge effect.

Through the network of this medium, graffiti has been obtaining different development model and situation from the previous, but also provide more opportunities for people to experience graffiti, the combination of the two media inevitably affect the human life, thinking and historical process.

The show of world view. Internet graffiti has the traditional graffiti of the catharsis and narrative, in real life, alienated people subconsciously more or less rebellious can also be found the channel to release in the network graffiti, they can put aside all the shackles, do not care about the views of others, enjoy the feelings of self-empathy and inner world, to express their own contempt to so-called authority and the mainstream, and show the value of self-world view. The platform that the network provides for the exchange and sharing is world-class, and encourage the experience complete the understanding and absorption of the world, to share their views and points of the world. For example, Figure (1) sketch the form of sketches out the characters, with a clear distinction between the color, through the contrast between the color to show author's heart monologue, the main body and the background of the subject text are clearly showing that the catharsis and resistance to the world view when the self-outer appearance of the experience get criticism through the network of graffiti.

The needs for emotional contact .Self-construction.In the network of graffiti activities, when the experience on the network to create and share, they build self-identity on the network. This identity is called "web self". Whether this identity is "complementary network I", that is, the extension of reality on the network; or "compensatory network I", that is, the role restricted by social reality can not play can be achieved in the network environment. Creation and sharing are the most basic means of construction, the network community is the most basic range of activities and places.

In the construction process of identity, it is inevitable to lead to personal experience, in personal experience to find "common memory" or "similar experience" and "identity". This is also the embodiment of the re-tribe trend, this new "identity" can create new groups, community relations; the meaning of previously maintained nationality and the country will be weakened. The self-construction of this

personal private experience is from the perspective of self-concept and observation, from the spiritual level to guide people to identity. (2) Author uses stupid style for the creation of the form, to create an abstract deformation of the characters in a mess of the hue, it is the performance of the experience of self-image depiction, to build a network image. This style is good at using naive, lovely, simple sense of

the design style to show that the author treats the problems lthrough a simple perspective on their own and the outside world, so that the creative experience of the process more casual, free and vivid. 


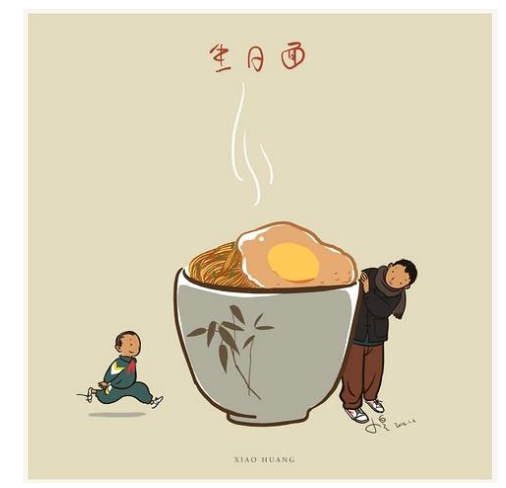

Figure 2. Totem spirit work

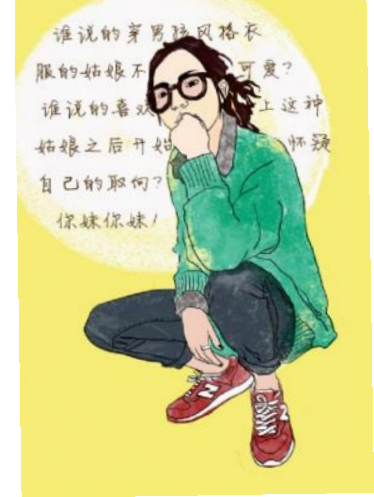

Figure 3. Totem spirit work

Community resonance

When people share a graffiti, even if the works do not belong to their originality, when they start sharing, they feel that they have been connected with the community. When people find other people also through them to share the same expression, they will form mutual understanding, community resonance was born. In the online community, the understanding between the tribal people may not be a complete understanding of the spirit, but the mutual support, help and exchange in the graffiti interaction, to achieve the degree of understanding, is the basis of community art atmosphere of harmony. Birthday map is the best representative of the community exchange, the experience in the network community to send birthday graffiti works in the other experience of the birthday. (3) the experimenter applies the Chinese painting lines into the actual situation, combined with Japanese-style gray tone, when the two characters, therein one is watching, another is running, where the movement highlights the happy atmosphere of the birthday; one side of the bowl is bamboo, and child is wearing a Chinese school uniforms, the perfect combination of regional and traditional are showed in the picture, natural and warm.

Social support

When the scale of "emotional connection" goes beyond the individual level and community level, it rises to the level of social movement, and creation and sharing are transformed into a weapon for seeking social support. Through the fast and wide network of graffiti interactive activities, the common feelings can get people together, micro-content to promote micro-action, micro-action brings micro-change.

Network graffiti in the absence of attention from mainstream media, release and deliver their own stories, before the public support has come, it forms unity emotion; the last possibility to achieve seems very slim, but community relationship through emotional network is enough to make the experience obtain interactive experience. 


\section{Conclusion}

Internet graffiti is a graffiti experience as a means of self-consolation and a cognitive human external world, is a mechanism to counter the stimulation and stress in real life, but from its totem spirit it can reflect the consciousness after refining of the state of mind, is transforming no shape and disorder world into a meaningful form, is the solution of inherent contradictions of online graffiti interactive experience, so that he wakes up from the confused and encouraged state, thoroughly change the passive and accepted attitude towards life, through this series of artistic creation activities for the world and the self understanding, and ultimately become the master of the spirit of self, and this positive initiative to pursue and the performance of complex emotion is the most important mental state of Internet graffiti, but also the most active role of the network graffiti in the real world.

\section{Acknowledgments}

Fund: Social Science Project of the Jingdezhen Ceramic Institute

\section{References}

[1] Arnold Hauser .Sociology of Art.Academia Press[M] ,1987

[2] Markel Blake .Comparison of deviant youth culture. [M]Beijing Institute of Technology Press ,1989

[3] Mcluhan.M. Understanding media [M].Commercial Press ,2000

[4] lvqiaoping .Medienkompetenz Chinesischer Jugendlicher[M],Communication University of China Press, 2007

[5] huyong.personal expression and public discussion in the internet age[M] Guangxi Normal University Press, 2008

*Corresponding author: : wu liu (1988-) female, nanchangjiangxi, , Jingdezhen Ceramic Institute theacher, Research: Digital Media Arts.E-mail: 258169989@qq.com 